\title{
Pré-compostagem de cadáveres de bovinos acometidos pelo botulismo $^{1}$
}

\begin{abstract}
Vera C.L.M. Curci ${ }^{2}$, Iveraldo S. Dutra ${ }^{3}$, Jürgen Döbereiner ${ }^{4}$ e Jorge Lucas Junior ${ }^{5}$
ABSTRACT.- Curci V.C.M., Dutra I.S., Döbereiner J. \& Lucas Junior J. 2007. [The effect of composting cattle carcasses on botulinum spores and toxin content.] Pré-compostagem de cadáveres de bovinos acometidos pelo botulismo. Pesquisa Veterinária Brasileira 27(4):157161. Unidade de Pesquisa e Desenvolvimento Tecnológico do Agronegócio, APTA Regional Extremo Oeste, Laboratório de Sanidade Animal, Av. Alcides Fagundes Chagas 122, Araçatuba, SP 15055-240, Brazil. E-mail: vlmcursi@aptaregional.sp.gov.br

Five carcasses of cattle that died from botulism were composted in individual isolated beds with the purpose of monitoring the effect on spores of Clostridium botulinum and of botulinum toxin. The diagnosis of botulinum poisoning was based on clinical and pathological, epidemic and/or laboratorial characteristics. Of the five bovines with clinical signs of chronic botulism, three were affected by the type $\mathrm{D}$ toxin, one by the $\mathrm{CD}$ complex, and one was negative for toxin and spores of $C$. botulinum in the viscera using a mouse bioassay. The composting process was carried out in beds with carcasses cut up and mixed with sawdust as a carbon source. They were kept anaerobic under a plastic sheet for 50 days. The temperature of the beds was monitored during the period and oscillated from 40.5 to $52.4^{\circ} \mathrm{C}$. After this time, soft tissue had complete decomposed with a significant loss of weight (26.5-44.5\%). The remaining bones no longer contained spores or botulinum toxin in the 5 samples taken from each carcass. Only 2 of the 200 samples of homogenized remaining ( 40 for each carcass) contained spores of $C$. botulinum type $C$. All samples were negative for botulinum toxin using the mouse bioassay. Composting carcasses of cattle that died from botulism eliminated botulinum spores and toxin from the remains.
\end{abstract}

INDEX TERMS: Composting, bovine carcasses, botulism, botulinum toxin C and D, Clostridium botulinum.

RESUMO.- Foram pré-compostados, em células individuais e isoladas, cinco cadáveres de bovinos acometidos pelo botulismo com a finalidade de monitorar a presença de esporos de Clostridium botulinum e de toxina botulínica antes e após o

\footnotetext{
${ }^{1}$ Recebido em 10 de agosto de 2006.

Aceito para publicação em 5 de dezembro de 2006.

Parte da Dissertação de Mestrado do primeiro autor junto ao Curso de Pós-Graduação em Medicina Veterinária, Faculdade de Ciências Agrárias e Veterinárias da Unesp, Campus de Jaboticabal, SP.

${ }^{2}$ Unidade de Pesquisa e Desenvolvimento Tecnológico do Agronegócio APTA Regional Extremo Oeste, Laboratório de Sanidade Animal, Av. Alcides Fagundes Chagas 122, Araçatuba, SP 15055-240. * Autor para correspondência: vlmcursi@aptaregional.sp.gov.br

${ }^{3}$ Depto Apoio, Produção e Saúde Animal, Curso de Medicina Veterinária, Unesp, Campus de Araçatuba, Cx. Postal 261, Araçatuba, SP 16050-680.

${ }^{4}$ Embrapa-CNPAB/Projeto Sanidade Animal, Seropédica, RJ 23890-000.

${ }^{5}$ Depto Engenharia Rural, FCAVJ, Unesp, Campus de Jaboticabal, Via de Acesso Prof. Paulo Donato Castellane s/nº, Jaboticabal, SP 14884-000.
}

processo de decomposição em leira estática com fonte de carbono. $\mathrm{O}$ diagnóstico da intoxicação nos animais foi baseado nas características clínico-patológicas, epidemiológicas ou laboratoriais. Dos cinco bovinos com evolução clínica crônica de botulismo, cujos cadáveres foram pré-compostados, três foram acometidos pela toxina tipo $\mathrm{D}$, um pelo complexo $\mathrm{CD}$ e um dos animais foi negativo na tentativa de deteç̧ão da toxina e de esporos da bactéria nas vísceras pelo bioensaio e neutralização em camundongo. $O$ processo de pré-compostagem foi realizado em leira estática, com o uso de material carbonáceo umidificado como substrato e esquartejamento do animal, vedado individualmente com lona plástica e sem aeração por um período de $\mathbf{5 0}$ dias. A temperatura das leiras foi monitorada durante o período e oscilou de $40,5-52,4^{\circ} \mathrm{C}$. Após a abertura das leiras, pôde-se constatar a completa decomposição de todo material mole, com redução significativa do seu peso (de 26,5-44,5\%), restando apenas os ossos. Não foi detectado esporo ou toxina botulínica no interior dos os- 
sos ( $\mathrm{n}=5$ para cada cadáver). Nas 200 amostras examinadas do homogeneizado restante ( $n=40$ para cada cadáver), em apenas duas amostras de uma leira foram detectados esporos de $C$. botulinum tipo $\mathrm{C}$, enquanto que todas foram negativas para a tentativa de deteção da toxina botulínica pelo bioensaio em camundongo. Da forma como foi avaliado o processo de pré-compostagem de bovinos mortos pela intoxicação botulínica não contribuiu para a proliferação de $C$. botulinum.

TERMOS DE INDEXAÇÃO: Compostagem, cadáver bovino, botulismo bovino, toxinas botulínicas C e D, Clostridium botulinum.

\section{INTRODUÇÃO}

Dentre as ações necessárias para a melhoria das condições ambientais e sanitárias na produção de carne e leite, a destruição de cadáveres de bovinos na propriedade rural é uma medida de grande importância. São diversas as causas e situações em que ocorrem mortes nos diferentes sistemas de produção, e dentre as mais freqüientes está o botulismo.

A enfermidade é uma das principais causas de mortalidade de bovinos em diversas regiões do país, em decorrência da intensificação da contaminação ambiental por Clostridium botulinum, da presença de cadáveres na pastagem e da osteofagia manifestada pelos bovinos deficientes em fósforo (Tokarnia et al. 1970, Döbereiner et al. 1992, Dutra 2001). A ocorrência do botulismo hídrico (Dutra et al. 2001), do botulismo associado ao emprego da cama de frango na alimentação animal (Dutra et al. 2005), assim como a ampla contaminação ambiental pelos esporos da bactéria em extensas regiões (Silva et al. 1998, Souza et al. 2006), principalmente a partir de cadáveres bovinos decompostos na pastagem (Souza \& Langenegger 1987, Ribas et al. 1994), complementam o raciocínio de que a inexistência de ações efetivas para se reduzir a possibilidade de intensificação da contaminação ambiental pela bactéria pode se traduzir em sérios prejuízos à bovinocultura.

A inexistência de legislação específica sobre a destruição de cadáveres nos sistemas de produção do país, a ausência de ações de educação sanitária pelos órgãos oficiais e o pouco conhecimento por parte dos produtores das consequiências sanitárias e econômicas de se deixar cadáveres entrarem em decomposição na pastagem complementam o quadro favorável à ocorrência da intoxicação.

Assim, a prática de se deixar cadáver bovino entrar em decomposição na pastagem, ou mesmo o seu enterro, coloca em risco a saúde animal e favorece a intensificação da contaminação ambiental por microrganismos potencialmente patogênicos. Os esporos de $C$. botulinum estão entre os mais resistentes esporos bacterianos, sobrevivendo mais de 30 anos em um meio fluido e provavelmente por mais tempo em um meio seco (Smith \& Sugiyama 1988).

Outra preocupação atual com a destruição de cadáveres de ruminantes nas propriedades rurais está relacionada com o cenário internacional e diz respeito ao risco potencial da encefalopatia espongiforme bovina (BSE) e das possíveis barreiras sanitárias. Embora não exista relato da sua ocorrência no país, a preocupação deve existir, uma vez que a disseminação da enfermidade ocorre predominantemente pela ingestão de resíduos de carcaça bovina contaminada com o agente etiológico. A osteofagia, a presença de cadáver em decomposição na pastagem e o desconhecimento das causas das mortes nas propriedades rurais passam também a ser potencialmente problemáticas quando se pretende observar as medidas preventivas para diminuir o risco potencial da doença e atender ao princípio da equivalência.

A exclusão dos animais mortos e de todas as matérias condenadas da cadeia alimentar dos animais de produção tem sido uma preocupação constante dos organismos governamentais europeus devido às implicações econômicas, ambientais e sanitárias que poderiam resultar na incorreta eliminação desses resíduos (Comissão das Comunidades Européias 2000). Assim, segundo esta Diretriz, a rastreabilidade perde totalmente o seu sentido quando animais entram em decomposição na pastagem, mesmo que enterrados.

O uso da compostagem de resíduos agropecuários é uma técnica que melhor condição oferece para se obter a rápida estabilização da matéria orgânica (Kiehl 1998). Este sistema promove a reciclagem do material inicial que retorna para o solo como fertilizante, além do fato de destruir bactérias patogênicas, vírus e parasitas (Hay 1996, Senne et al. 1994).

Na literatura consultada inexiste menção sobre os efeitos da compostagem de cadáveres de bovinos acometidos pelo botulismo na recuperação de esporos da bactéria e detecção de suas toxinas após o processo. Diante da necessidade de se avaliar e implantar medidas alternativas para a correta destruição de cadáveres bovinos nas propriedades rurais, visando a saúde do rebanho e a preservação ambiental, o presente trabalho teve por objetivo verificar a viabilidade do Clostridium botulinum e suas toxinas após o processo de pré-compostagem em leira estática de cadáveres de bovinos acometidos pelo botulismo.

\section{MATERIAL E MÉTODOS}

Os bovinos, cujos cadáveres foram empregados no presente trabalho, foram oriundos de propriedades rurais da região de Araçatuba, SP, e apresentavam suspeita clínica inicial de intoxicação botulínica. Os animais foram encaminhados ao Setor de Enfermidades Infecciosas dos Animais da Unesp por médicos veterinários, onde foram acompanhados na sua evolução clínica até a morte. Os parâmetros para a avaliação clínica dos cinco animais, do processamento dos materiais coletados para a tentativa do diagnóstico etiológico e para a deteç̧ão de esporos de Clostridium botulinum no trato gastrintestinal foram os empregados por Dutra (2001). Nenhuma medida de tratamento específico ou mesmo geral foi implementada.

\section{Pré-compostagem}

Definiu-se como pré-compostagem o tratamento prévio de cadáver bovino pelo período de 50 dias em leira estática individual com material carbonáceo (Fig.1 e 2). Este tratamento compreendeu a fase anaeróbia do processo, ou seja, a fase inicial do processo de compostagem propriamente dita. A metodologia aplicada foi a da compostagem natural, sem aeração, até a decomposição total do tecido mole do cadáver, conforme descrito por Pedroso de Paiva \& Bley Junior (2001). O período de 50 dias foi arbitrado considerando- 
se que na literatura compulsada a decomposição de cadáveres, e conseqüientemente a diminuição da matéria orgânica e da heterogeneidade do material, ocorreria neste período.

As leiras foram montadas individualmente em local coberto, em dias diferentes, de acordo com a disponibilidade de cadáveres de bovinos acometidos pelo botulismo. O material carbonáceo empregado foi a maravalha na relação de 11 litros $/ \mathrm{kg}$ de carcaça. $\mathrm{O}$ peso e/ou a dimensão das leiras variaram de acordo com o peso de cada cadáver, sendo quantificado com o auxílio de uma balança. Para melhor acomodação os cadáveres foram esquartejados, tendo-se o cuidado de colocar as vísceras brancas no centro da pilha, simulando a condição natural em que ocorre a decomposição. As leiras foram recobertas (envelopadas) com uma lona plástica com a finalidade de manter o sistema isolado durante o processo. A quantidade de água adicionada na montagem das leiras foi calculada a partir da quantidade de carcaça e da umidade da maravalha adicionada, utilizando-se a fórmula recomendada por Kiehl (1998) para que o material ficasse próximo de $50-60 \%$ de umidade. Entretanto, as leiras foram montadas com excesso de carbono (maravalha) e com pouca adição de água devido à quantidade de água e nitrogênio nas carcaças, além da heterogeneidade do material inicial (carne, ossos,

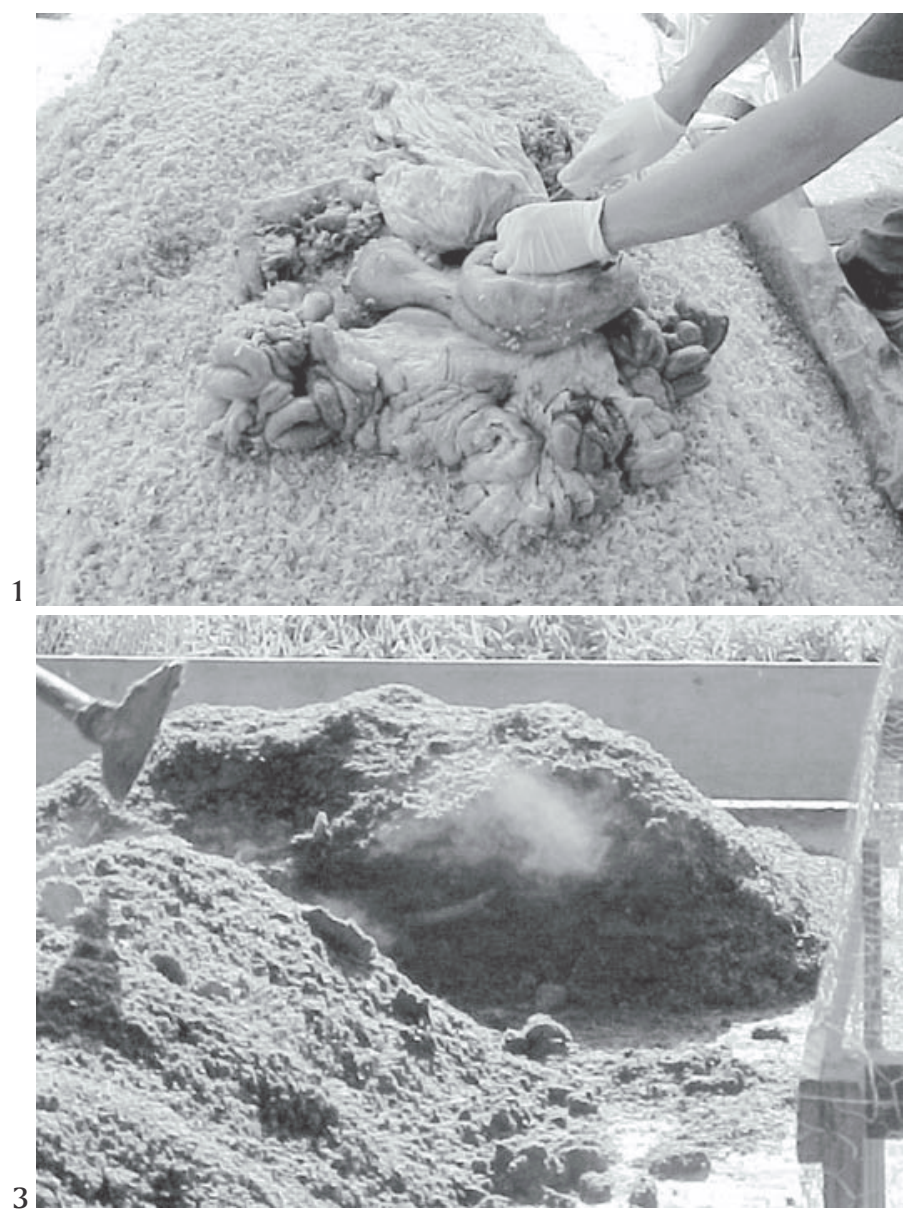

Fig.1. Montagem da leira em camadas alternadas de fragmentos de cadáver bovino e maravalha (fonte de carbono), com o intestino sendo colocado ao centro da pilha.

Fig.3. Revolvimento da leira após 50 dias de pré-compostagem para avaliação da contaminação do homogeneizado e das costelas pelos esporos e toxinas de Clostridium botulinum. vísceras, conteúdo estomacal e intestinal, couro). A temperatura foi aferida uma vez ao dia utilizando-se de termômetro digital e avaliada pela média de dez aferições em diferentes pontos de cada leira.

Após o período de 50 dias, as leiras foram abertas e o material revolvido no próprio local para sua homogeneização e oxigenação (Fig.3 e 4) e coleta das amostras (homogeneizado e costelas). $O$ peso das leiras foi avaliado no início (na montagem) e aos sessenta dias do processo (10 dias após a abertura das leiras).

\section{Deteç̧ão de esporos e/ou toxinas de Clostridium botulinum}

Para a tentativa de diagnóstico laboratorial do botulismo foram coletadas amostras das vísceras dos animais. Foram coletadas amostras de fígado (aprox.100g), conteúdo ruminal $(20 \mathrm{ml})$ e de conteúdo intestinal $(20 \mathrm{ml})$ de cada animal. Nos dois últimos materiais foi avaliada indiretamente a presença de esporos da bactéria. Os conteúdos ruminal e intestinal foram coletados por meio de punção do rúmen ou intestino com agulha e seringa, procurando-se assim mantê-los na sua integridade. Estas amostras foram avaliadas para a presença de esporos $(n=25$ para cada material) e toxina $(n=5$ para cada material). Foi analisada ainda para a presença de esporos uma amostra composta $(10 \mathrm{~g})$ de cada leira do material carbonáceo

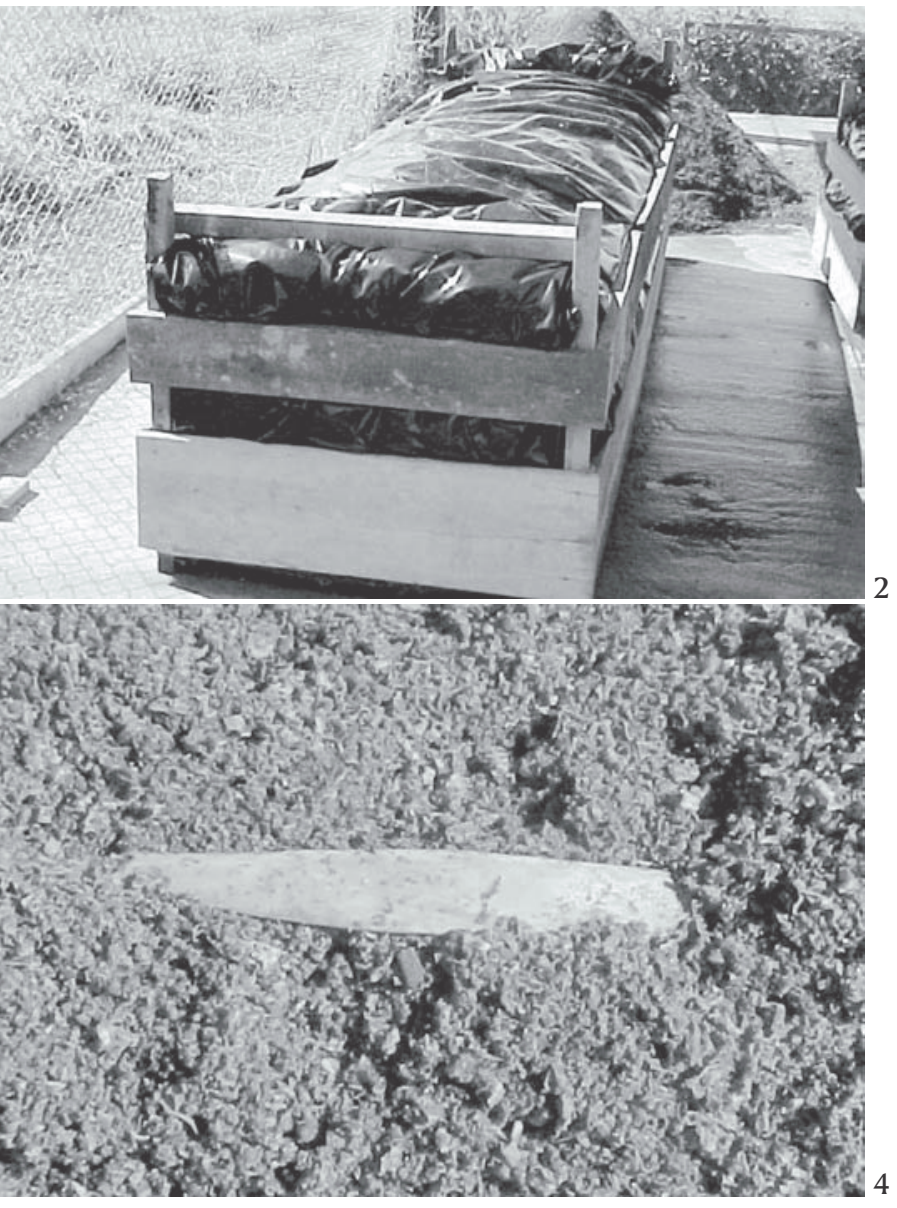

Fig.2. Leira fechada após a acomodação do material para o início do processo de pré-compostagem em pilha estática e sem aeração.

Fig.4. Costela livre de tecido, observada após a abertura de leira aos 50 dias do início da pré-compostagem de cadáver bovino 
(maravalha) in natura e utilizado no processo. Após a abertura e a homogeneização da(s) leira(s), foram coletadas aleatoriamente 40 amostras $(1 \mathrm{~kg})$ do pré-composto ou composto imaturo, e cinco costelas de cada animal pré-compostado, quando estas se apresentavam limpas de todo tecido macio. $\mathrm{O}$ processamento das costelas para detecção de esporos e toxinas botulínicas foi de acordo com a metodologia descrita por Ribas et al. (1994). As amostras foram identificadas, acondicionadas em sacos plásticos e transportadas para o laboratório, onde permaneceram sob congelamento $\left(-20^{\circ} \mathrm{C}\right)$ até o seu processamento.

Esporos de Clostridium botulinum. As amostras coletadas foram semeadas em Cooked Meat Medium (CMM). Os meios de cultura recém-semeados com as amostras $(1 \mathrm{~g})$ foram aquecidos em banhomaria a $80^{\circ} \mathrm{C}$ por $10 \mathrm{~min}$. para eliminação de contaminantes e ativação dos esporos. Após o resfriamento em meio ambiente, os tubos foram mantidos em anaerobiose à temperatura de $37^{\circ} \mathrm{C}$ por um período de 5-7 dias. Após este período, o sobrenadante da cultura foi centrifugado a $3.000 x$ por 10 minutos e filtrado em Millipore $(0,45 \mathrm{~mm})$. A presença de Clostridum botulinum foi detectada indiretamente pela verificação da toxina botulínica no meio de cultura pelo bioensaio e a neutralização em camundongo com as antitoxinas botulínicas homólogas.

Toxina botulínica. As amostras foram avaliadas para a presença de toxina botulínica com o emprego do bioensaio em camundongo. Para a eluição da toxina, foi necessário triturar uma porção de cada amostra analisada com solução de $\mathrm{NaCl}$ a $0,85 \%$ na proporção $1: 1$, e mantê-la sob refrigeração por 12-24 h. Após este período, $10 \mathrm{ml}$ da solução foram centrifugados a $3.000 x g$ durante 10 minutos para a realização do bioensaio. O sobrenadante, filtrado em Millipore $(0,45 \mathrm{~mm})$, foi inoculado via intraperitoneal $(0,5 \mathrm{ml})$ em camundongo da raça Swiss albina, linhagem Webster, com peso corporal variando de 20-25g. Como controle foram inoculados camundongos com os mesmos materiais aquecidos a $100^{\circ} \mathrm{C}$ por 20 minutos para inativação de toxina botulínica eventualmente presente. Os camundongos inoculados foram observados por um período de 3 dias para a verificação de sinais clínicos sugestivos do botulismo.

Neutralização em camundongo. Os materiais que provocaram mortes com sintomatologia clínica foram submetidos ao teste de neutralização em camundongo para tipificação das amostras, segundo Dowell \& Hawkins (1974). As antitoxinas utilizadas foram obtidas do Center for Disease Control, Atlanta, Georgia, Estados Unidos da América. O tipo específico foi determinado quando sobreviveu o camundongo inoculado com antitoxina homóloga à toxina presente no material. Em caso de neutralização com os dois tipos (C e D), o material foi classificado como sendo pertencente ao complexo $\mathrm{CD}$.

\section{Análise estatística}

O teste t pareado (Zar 1998) foi empregado para comparar o peso inicial das leiras e aos 60 dias de processo. A análise estatística foi efetuada empregando-se o programa SAS (1999).

\section{RESULTADOS E DISCUSSÃO}

$\mathrm{Na}$ avaliação das alternativas para a destruição de cadáveres nos sistemas de produção deve-se considerar a pratici-dade do processo e as suas possíveis implicações ambientais e sanitárias. A facilidade em se encontrar fontes de carbono, a pouca complexidade do processo e o fato de promover a reciclagem segura da matéria orgânica, transformando-a em fertilizante, viabilizam a compostagem como biotecnolo-gia que atende aos princípios da sustentabilidade. Fatores como o tem- po e a temperatura do processo inviabilizam diversos microrganismos potencialmente patogênicos (Senne et al. 1994, Hay 1996). No entanto, são desconhecidos os efeitos da compostagem sobre a viabilidade dos espo-ros de Clostridium botulinum. Embora Böhnel \& Lube (2000) tenham encontrado esporos da bactéria em mais de 50\% das 91 amostras avaliadas de composto comercial doméstico na Alemanha, e ainda a presença de toxina livre em algumas amostras, a situação difere da do objeto do presente trabalho.

Dos cinco bovinos com evolução clínica crônica e précompostados, três foram acometidos pela toxina botulínica tipo D e um pelo complexo CD. Em apenas um dos animais não foi possível realizar a comprovação laboratorial da intoxicação pela detecção da toxina botulínica em pelo menos um dos materiais examinados. No entanto, diante desta situação o diagnóstico laboratorial negativo não exclui a possibilidade da intoxicação, prevalecendo o diagnóstico clínicopatológico e epidemiológico. Esta particularidade deve-se à sensibilidade do bioensaio em camundongo, que é de $43,1 \%$ quando se analisam amostras de fígado e conteúdos ruminal e intestinal de bovinos suspeitos (Dutra 2001) e ainda à alta suscetibilidade dos bovinos diante da toxina botulínica tipo $\mathrm{C}$, quando comparados com os camundongos que são 12,88 vezes menos sensíveis (Moeller et al. 2003)

Por outro lado, a presença de esporos de $C$. botulinum tipo $\mathrm{C}$ nos conteúdos ruminal e intestinal foi confirmada somente em um dos cinco bovinos avaliados. Este aparente paradoxo entre os tipos de toxina envolvidos na intoxicação e a bactéria presente no trato gastrintestinal deve-se, provavelmente, às características do botulismo bovino, em que os dois tipos (C e D) são os responsáveis pela intoxicação, podendo inclusive ser encontrados normalmente na microbiota intestinal, ou ainda pelo pequeno número de amostras avaliadas. Como houve a preocupação em manter a integridade do trato gastrintestinal por ocasião da pré-compostagem, a coleta dos conteúdos foi por punção localizada, restringindo assim a representatividade da amostra. Tal fato pode inclusive ter influenciado nestes resultados, uma vez que Dutra (2001) obteve a positividade em todas as tentativas de detecção de esporos da bactéria no intestino de animais com sintomatologia clínica da intoxicação.

Embora não represente as condições naturais da decomposição de cadáveres, o esquartejamento dos animais nesta etapa da avaliação foi em decorrência da facilidade de acomodação das peças em um sistema experimental fechado (Fig.2) e da otimização da relação entre a fonte de carbono e o material a ser compostado, possibilitando a avaliação do processo. No entanto, procurou-se manter as vísceras no centro do dispositivo (Fig.1), simulando assim uma situação aproximada do que ocorre em condições normais.

A temperatura média das leiras oscilou de $40,5-52,4^{\circ} \mathrm{C}$ na maioria dos 50 dias do processo estático e sem aeração. Na abertura e revolvimento das leiras, pôde-se observar que as carcaças foram praticamente decompostas, restando apenas os ossos (Fig. 4). A redução do peso das leiras após o período de pré-compostagem variou de $26,5-44,5 \%$. Os valores da média e do desvio padrão do peso inicial das leiras e aos 60 dias 
foram de $557,8 \mathrm{~kg} \pm 159,0 \mathrm{~kg}$ e $347,2 \mathrm{~kg} \pm 103,6 \mathrm{~kg}$, respectivamente, e a redução foi de $37,7 \pm 6,8 \mathrm{~kg}$. 0 teste t pareado evidenciou uma significativa redução do peso $(\mathrm{P}=0,0027)$ das leiras, o que indica que um dos objetivos do processo também foi atingido na pré-compostagem, ou seja, a redução significativa da massa de músculos, vísceras e outros tecidos moles, decompondo-os nesta fase mais crítica da compostagem. Segundo Looper (2001), na compostagem é possível a decomposição de 60-65\% dos cadáveres de bovinos.

Não foram detectados esporos ou toxinas de $C$. botulinum no interior das 25 amostras de costelas examinadas dos cinco cadáveres após o processo da pré-compostagem. Evidentemente que as condições encontradas por este microrganismo putrefativo em cadáveres em decomposição natural não são as mesmas que para os cadáveres envolvidos com a fonte de carbono, ressaltando-se ainda que foram esquartejados. Ribas et al. (1994) verificaram a presença de esporos e toxinas de $C$. botulinum em $46,5 \%$ das amostras de costelas de cadáveres de bovinos supostamente acometidos pelo botulismo e decompostos naturalmente nas pastagens. Portanto, tendo-se como parâmetro a possibilidade concreta de invasão da medula óssea das costelas pelo microrganismo e eventual formação de toxina em condições naturais, pôde-se constatar que a pré-compostagem de alguma forma impossibilitou este evento.

No total das 200 amostras do homogeneizado, provenientes dos cinco cadáveres decompostos, nenhuma foi positiva para a presença de toxina botulínica. Na deteç̧ão de esporos da bactéria, apenas 2 amostras (1\%) de um dos cadáveres foram positivas para o tipo C. Como também não foram detectados esporos nas 25 amostras de maravalha analisadas e empregadas na pré-compostagem, pode-se deduzir pela aparente segurança do processo quando executado nas condições experimentais aqui descritas.

Os resultados da análise do homogeneizado coletado após a decomposição aparente do material mole evidenciam que o processo não viabilizou a multiplicação de $C$. botulinum ou a formação de toxina. Ou mesmo se isto ocorreu, não pode ser evidenciado ao final de aproximadamente 50 dias com a temperatura média das leiras oscilando de $40,5-52,4^{\circ} \mathrm{C}$. Segundo Haug (1993), Kiehl (1998), Senne et al. (1994), a compostagem tem como um dos objetivos a inativação térmica de patógenos; não sendo encontrado na literatura consultada nenhuma referência relacionando $C$. botulinum com a compostagem de cadáveres.

São vários os questionamentos sobre como o processo biotecnológico da compostagem, com a participação de diversos microrganismos, interfere para inibir ou inviabilizar a multiplicação de $C$. botulinum com a conseqüente formação da toxina botulínica. Cabe ressaltar que a avaliação da presença de esporos e toxinas de $C$. botulinum após a pré-compostagem deveu-se ao fato de que hipoteticamente seriam oferecidas neste período as melhores condições para a bactéria se multiplicar, devido ao processo de decomposição dos cadáveres em leira estática e sem aeração.

\section{REFERÊNCIAS}

Böhnel H. \& Lube K. 2000. Clostridium botulinum and bio-compost: a contribution to the analysis of potential health hazards caused by biowaste recycling. J. Vet. Med. 47:785-795.

Comissão das Comunidades Européias. 2000. Proposta de regulamento do Parlamento Europeu e do Conselho que estabelece as regras sanitárias aos subprodutos animais não destinados ao consumo humano. [Online] http://www.europa.eu.int. Acessado em 20 de fevereiro de 2002.

Döbereiner J., Tokarnia C.H., Langenegger J. \& Dutra I.S. 1992. Epizootic botulism of cattle in Brazil. Dtsch. Tierärztl. Wochenschr. 99(5):188-190.

Dowell V.R. \& Hawkins T.M. 1974. Laboratory Methods in Anaerobic Bacteriology: CDC laboratory manual. U.S. Department of Health, Education and Welfare, Center for Disease Control. Atlanta, Geórgia, USA. 96p.

Dutra I.S. 2001. Epidemiologia, quadro clínico e diagnóstico pela soroneutralização em camundongo do botulismo em bovinos no Brasil, 1989-2001. Tese de Livre Docência, Curso de Medicina Veterinária, Unesp, Campus de Araçatuba, São Paulo. 133p.

Dutra I.S., Döbereiner J. Rosa I.V., Souza L.A.A. \& Nonato M. 2001. Surtos de botulismo em bovinos no Brasil associados à ingestão de água contaminada. Pesq. Vet. Bras. 21(2):43-48.

Dutra I.S., Döbereiner J. \& Souza A.M. 2005. Botulismo em bovinos alimentados com cama de frango. Pesq. Vet. Bras. 25(2):115-119.

Haug R.T. 1993. The practical handbook of compost engineering. Lewis, Boca Raton. 717p.

Hay J.C. 1996. Pathogen destruction and biosolids composting. Biocycle 37(6):67-76.

Kiehl E.J. 1998. Manual de Compostagem: maturação e qualidade do composto. E.J.Kiehl, Piracicaba, São Paulo. 171p.

Looper M. 2001. Whole animal composting of dairy cattle. Extension Dairy Specialist, New MexicoStateUniversity.[Online].http://dairybusiness.com/ western/Nov01/NovWDBcompost.htm. Accessed 18 July 2003.

Moeller Jr. R.B., Puschner B., Walker R.L., Rocke T., Galey F.D., Cullor J.S. \& Ardans A.A. 2003. Determination of the median toxic dose of type $C$ botulinum toxin in lactating dairy cows. J. Vet. Diag. Invest. 15(6):523-526.

Paiva D.P. \& Bley Junior C. 2001. Emprego da compostagem para destinação final de suínos mortos e restos de parição. Circular Técnica, Embrapa Suínos e Aves, Concórdia. 26p.

Ribas A.I., Ferreira R.M.M., Masser R.C., Ciani R.B. \& Dutra I.S. 1994. Detecção de esporos de Clostridium botulinum em costelas de cadáveres decompostos de bovinos. Anais $23^{\circ}$ Congr. Bras. Med. Veterinária, Olinda, Pernambuco, p.142. (Resumo)

Sas Institute. 1999. SAS OnlineDoc ${ }^{\mathrm{R}}$ : version 8. SAS Institute Inc., Cary, NC.

Senne D.A., Panigrahy B. \& Morgan R.L. 1994. Effect of composting poultry carcasses on survival of exotic avian viruses: highly pathogenic avian influenza (HPAI) virus and adenovirus of egg drop syndrome-76. Avian Dis. 38(4):733-737.

Silva T.M.D., Dutra I.S. Castro R.N. \& Döbereiner J. 1998. Ocorrência e distribuição de esporos e toxinas de Clostridium botulinum tipos C e D em áreas de criação de búfalos na Baixada Maranhense. Pesq. Vet. Bras. 18(3/4):127-131.

Smith L.D.S. \& H. Sugiyama. 1988. Botulism: the organism, its toxins, the disease, 2nd ed. CharlesThomas, Springfield. 171p.

Souza A.M. \& Langenegger J. 1987. Esporos de Clostridium botulinum em torno de cadáveres decompostos de bovinos em pastagens no sul de Goiás. Pesq. Vet. Bras. 7(1):17-22.

Souza A.M., Marques D.F., Döbereiner J. \& Dutra I.S. 2006. Esporos e toxinas de Clostridium botulinum dos tipos C e D em cacimbas no Vale do Araguaia, Goiás. Pesq. Vet. Bras. 26(3):133-138.

Tokarnia C.H., Langenegger J., Langenegger C.H. \& Carvalho E.V. 1970. Botulismo em bovinos no Piauí, Brasil. Pesq. Agropec. Bras. 5:465-472.

Zar J.H. 1998. Bioestatistical Analysis. 4th ed. Prentice-Hall, New Jersey. 930p. 